\title{
The Impact of ICT on Learning at a Distance Working Group 3.6
}

\author{
Chair: Elizabeth Stacey (AU) \\ Rapporteur: Vicki Lowery (AU) \\ Participants: Jenny Arms (AU), Mark Beach (NZ), Charlotte Cederstrøm \\ (DK), Erik Dam (DK), Lone Dirckinck-Holmfeld (DK), France \\ Henri (CA), Petera Hudson (NZ), Soini Kari (DK), Ove \\ Bardenfleth Nielsen(DK), Kim Fuglsang Østergaard (DK)
}

Keywords: culture, distance learning, electronic communication, pedagogy, teacher training

\begin{abstract}
Information and Communication technologies have helped to remove the isolation of learning at a distance and changed the nature of distance education. The discussion examined this change and how it has affected school, college and higher education students who have no choice but to learn at a distance as well as those who are choosing to use ICT for flexible access to online classes and resources. Four major themes emerged: Acculteration, Authentication and the flexibility of design of hardware and software, Support, management and professional development of distance education teachers and Flexibility of leaming for adults through ICT. An over-riding theme was the effects of culture on the use of ICT for education.
\end{abstract}

\section{INTRODUCTION}

The advent of the Internet and the capability of a global network of computers have radically changed the nature of distance education. Learning at a distance was traditionally a response to barriers such as geographic remoteness or physical inability to participate in face-to-face classes and was particularly prevalent in countries where small pockets of the population was scattered over large distances such as in Australia and Canada. Distance learning has always been inextricably linked with technology from the use of early forms of text reproduction to use of telephone, radio and television to 
facilitate production, distribution and interaction. Countries with large, scattered populations were also able to use methods of distance learning to provide education more widely as technologies were developed. Countries such as China and Turkey have been able to use television as a means of reaching learning and distributing education.

However, none of these technologies have had the impact on distance learning that Information and Communication technologies, with the resultant networking of computers in every country of the world, has had on education today. Now every country is using distance education even if their learners are able to access traditional face to face education, as is often the case in parts of Europe and Scandinavia. All teachers are now having to learn effective strategies for distance learning and the concept of globally connected learners has resulted in global distance learning through virtual campuses that can enable access to any education institution in the world or exist only within the networked computers.

Such capabilities mean that learning by Internet-linked computers are seen by governments as a solution to their provision of education and by educational entrepreneurs as a way of providing international markets for education and training. This international distance education market is sought by both traditional institutions seeking students world-wide and by commercial institutions developed for the process of virtual learning. As all levels of education embrace distance education strategies, the impact of ICT use on this type of learning must be considered in all contexts.

\section{Schools}

- Teachers and students have had to learn new skills and work practices. Teachers have had to learn to deliver classes to students they could not see, creating new challenges for classroom management.

- Teachers also had to achieve skills in technology so that they had sufficient confidence to deliver their classes to their distant students.

- Students have had to learn a new range of communication skills using telephone, e-mail, video-conferencing and discussion forums.

- Combining face-to-face and distance education: It is easy for the teacher and class to forget the distant students just as it is difficult for distant students to keep their focus on a teacher/class they cannot see.

\section{Vocational Education and Training}

Introducing workplace training linked to programs taught from colleges of vocational education through ICT has opened up a range of issues about learning and learning support. Professional development of staff and development of students into self directed, independent learners who can engage with learning online is often a challenge particularly in practical vocational skills education. Institutes have needed to focus on digital network development, Web site development, professional development of 
staff -for teaching and student support, management systems for delivery, access and equity issues, and project co-ordination between workplaces and colleges.

\section{Universities and Institutes of Higher Education}

Principles of adult education and self directed, independent learning are again a feature of learning at a distance in higher education. Experiences of traditional institutions now entering this area as they provide programs online can be informed by the distance education universities and their adaptation to ICT over the past decades. Issues raised include:

- Collaborative learning and the development of a learning community at a distance is now possible with ICT and this has changed the way distance learners linked to universities now learn.

- The resource base now possible through databases and World Wide Web sites has also greatly changed their ability to research at a distance and libraries are now centres of ICT expertise and equipment.

- The support infrastructure required to provide quality higher education at a distance is of major importance to the success of virtual campuses.

The three issues for in the group discussion focused on:

- Removing isolation through use of ICT;

- Effects of change to distance leaning on both teachers and learners;

- Combination uses of ICT for on campus as well as distance students. Participants were asked to consider the following factors in relation to each of the above and respond with reference to their country's perspective.

1. Development and delivery of distance learning: critical success factors.

2. Emerging technologies: what works, what has been trialled, what are the pitfalls?

3. Effectiveness of online learning: strategies that work - how to engage the learner?

4. Student and teacher perspectives on learning: examples of successes, failures, works-in-progress - both remotely and as a support to face-toface classes.

The group was diverse, covering a range of educational backgrounds.

While everyone's work revolves around a common theme of 'distance learning using ICT' there were several themes which participants were keen to explore further.

- Acculturation One group discussed the issue of 'culture' and the need to protect a culture and its language from the effects of globalisation. Participants in this group include a French speaking research director from Canada, a New Zealander involved in teacher professional development of Maori teachers and a Danish research professor who all agreed that there is a need to resist these negative influences. 
- Flexibility of learning for adults through ICT In Denmark as in many European countries distance is not the issue but rather how to provide flexibility of access to all learners, no matter what their circumstances. This group included a program director for vocational education in Denmark and an IT co-ordinator for a teacher training institution in Denmark.

- Authentication and the flexibility of design of hardware and software Group members included a project manager with the Danish Standards Association, a system developer with the Danish defence department and a former teacher now developing educational software.

- Support, management and professional development of distance education teachers The members were the principal of the New Zealand Correspondence School and an Australian project officer managing the use of video conferencing in schools. Their focus was on reliable and appropriate technology suited to the content, support for teachers and students and the good management of the whole process.

The group facilitator teaches and researches professional educators online as well as teaching pre-service teachers the use of flexible delivery. The rapporteur develops and delivers professional development programs using a variety of ICTs to teachers in the school and technical education sectors.

While the themes appear disparate, participants agreed that their discussions emanated from their original talk on the impact of ICT on learning at a distance. Because of their varied backgrounds, skills and experiences, participants found it easier to break into groups to focus their discussions.

\section{RESISTANCE AGAINST GLOBALISATION}

As Mason (1998) explains, globalisation of education is taking place along with the globalisation of economy with all that the consequences that follow. Supported by the development of ICT, the globalisation movement in education could have strong positive effects: enriching learning environments, opening up classrooms an schools to the world, allowing global interaction among learners and among educators to share ideas and culture. For educational institutions, ICT offers interesting opportunities to develop new alliances, set up creative ways for the sharing of resources, and reduce costs. However, Mason also stresses that globalisation has negative effects by introducing the notion of education as a 'market', by imposing competition among institutions to gain more 'clients', and by carrying out usage of ICT as a sales gadget instead of an added value to learning. 
Our reflection led us to insist on the necessity to become very much aware of the negative influence of ICT mainly because it is insidious, not easily observable. Technology is not neutral. Each tool, each system carries out values and a certain vision of man and of human activity that is not without influence on users and on the culture of the users. Since ways of knowing the world and learning about it is an intimate part of culture, we should be in control of it, and not let technology influence it without our consent. We want to prevent ICT tools, products and services threatening the education process by imposing unwanted transformations, by making it a prisoner of the 'screen culture', and by levelling and limiting our vision of the world to 'unique thinking', unique language and unique sets of value.

A prime example the invasion of computer positivist culture is given by the Maori learners in New Zealand who are expected to use the English version of computer applications to assist in the achievement of a learning outcome. However the medium of the screen culture is not adapted to their way of experiencing the world through their language. Work is being done in close association with Hawaiian colleagues, who are working on similar challenges. Associations with web browser and desktop publishing application publishers are being forget so that the 'faces' of applications are at least in the Maori language medium. But much more should be done.

Culture could be defined by the way of knowing and of communicating; it is not limited to ethnic differences. Our 'problematic' as educators, as technology users and as technology developers should be on a day-to-day basis to find ways and means to:

- Trace acculturation of the learning process generated by ICT

- Resist against the standardisation of learning suggested by ICT tools, products and services

- Maintain and promote the diversity of 'learning cultures'.

For that purpose, we should work towards the development of an acute and critical understanding of ICT in order to depict subliminal invasion of learning by undesirable values and ways of thinking embedded in ICT. Supportive professional development programmes could carry on such critical attitude towards technology as well as initial ICT curriculum for the training of computer specialist and computer users.

We should also urge technology developers to apply participative design methodology in order to involve ICT users in the creation of tools that are respectful of their culture and values. Learn-Net (Charlier and Peraya 2001) is a European project that gives an example of collaboration between technology developers and users to for the setting up of a virtual campus shared by $\mathrm{X}$ university from $\mathrm{Y}$ different country. 


\section{FLEXIBILITY OF LEARNING FOR ADULTS}

In Denmark as in many European countries distance is not the issue but rather how to provide flexibility of access to all learners, no matter what their circumstances. In Denmark the possibilities of getting access to the Internet are very good. The following figures from "Danmarks Statistik" 7. May 2001, indicate the state.

\begin{tabular}{|c|c|c|l|}
\hline $\begin{array}{l}\text { Access to internet, } \\
\text { either at work or } \\
\text { home }\end{array}$ & $\begin{array}{l}\text { Access to internet, } \\
\text { either at work or home, } \\
\text { family with children }\end{array}$ & PC at home & $\begin{array}{l}\text { PC at home, family } \\
\text { with children }\end{array}$ \\
\hline $72 \%$ & $80 \%$ & $70 \%$ & $90 \%$ \\
\hline
\end{tabular}

On the other hand are there some problems around high speed access, only $10 \%$ have more than 50 kbits lines.

When considering the issues above, we felt that it is important to look at the following key focus points for learning:

1. The process is more important than the outcome

2. Learning is always based on the experience, and is lifelong process

3. Learning is a conflict-filled process, challenging the individual's knowledge and experience

4. Learning must be a holistic and critical process, with feedback

5. Interaction between the learner and the environment is necessary for learning

6. Learning must have interaction between social knowledge (collective knowledge) and personal knowledge

7. Learning has to make sense

8. Learning needs motivation (wanting to)

9. Learning needs a loving and positive climate

10.The learning process has to be flexible, so the individual can learn in her own way and at times and places of his/her own choosing.

We outlined four main areas for work when doing an e-learning project:

1. Planning and developing an e-learning course

2. Quality assurance of your e-learning course project

3. Delivering and coaching your e-learning course

4. Evaluation programs/tools.

At Niels Brock Business College, Copenhagen, Denmark, a System Development course taught at undergraduate level used a problem based learning approach online with 50 students working in small groups on projects with real life application on corporate contexts. Student retention rate is usually only $50 \%$ when the course is taught face to face. During the course there are three face to face meetings for $1 / 2$ a day at the beginning, 
half way and at a roundup point in the semester spaced. Between these meetings there is an online conferencing structured with collaborative groups with mature age female leaders. The assessment is both collaborative and individual with a final examination and a defence of the group report. There was a $10 \%$ better grade average than when run traditionally with only 2 students dropping out of the course.

It was successful because of student leadership, authentic tasks, and ongoing online communication throughout the semester. The quality of teaching rose with web based teaching as resources were developed for students in a public and accountable medium, and teaching online raised pedagogical reflection amongst teachers as they began teaching in a new environment.

At Deakin University, Australia, a detailed evaluation of the use of computer conferencing for units established in a Master of Professional Education and Training program was undertaken as part of a project, Learner Centred Evaluation of Computer Facilitated Learning Projects in Higher Education, which was funded by the Australian Commonwealth government Committee of University Teaching and Staff Development. The structuring of the units and their effects on interaction and learning online found:

- Student feedback supported the use of online conferencing in encouraging a learning community with teacher presence seen as central.

- Frequency analysis showed that required online involvement generated high frequency of messaging, a high teacher time requirement that needed more management with responsibility given to students. Patterns of communication showed that high teacher interaction encouraged high student response but in small groups this was devolved and required less teacher interactivity.

- Tasks designed for online discussion generated online interaction with a cognitive focus.

- Content analyses pointed to the importance of conferences for social interaction and administrative sharing as well as for a cognitive focus.

- Students perceived the value of considering other students' perspectives, ideas and resources as a component of their successful learning online.

\section{AUTHENTICATION AND THE FLEXIBILITY}

In the traditional way of teaching where the students show up in a classroom they can be recognised and identified by the teacher who generally has a reasonable idea of the abilities of the individual student. This is not the case when we speak of learning at a distance. In this case the teacher may never face the student and does not know very much about 
them. The teacher does not know if somebody else than the registered person is doing the training and taking the tests. An authentication process therefore needs to be put in place. The tests/examinations need to be electronically signed to prove that the right person was at least present at the test. This technical problem belongs to the generic design of the tools used. Systems with electronic signatures and certificates may solve the problem and ensure both the students and the teachers that the identification and credibility is present.

This is an important component of the design of an ICT application and is influential in ensuring the success of the ICT application. We are not able to start using ICT in any organisation without influencing the organisation and/or the goals of the organisation. We are not able to use ICT in any process without influencing the process and/or the goal or purpose of the process. We also need to consider whether ICT forces us to redefine what learning is? Many things we learn are outdated in a short period of time.

Leavitt (1965) developed a diamond model trying to show that changing any part (corner) of the system makes an impact on the other corners.

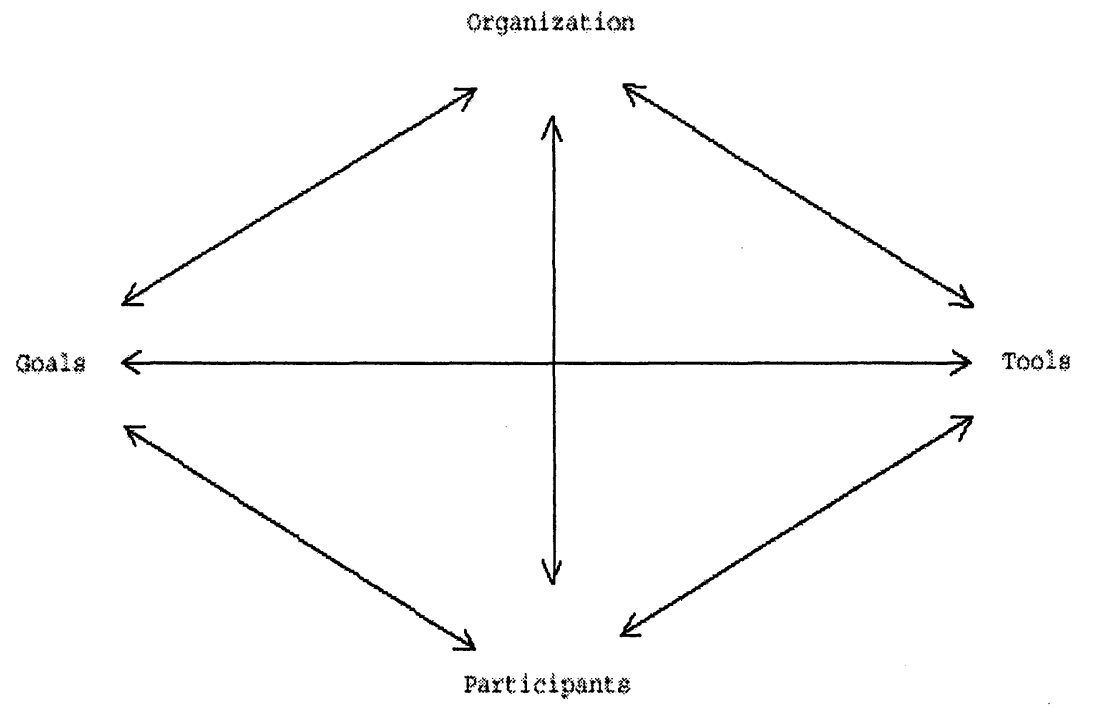

In designing and developing learning system/environment it is important the teachers/users are involved in this process as soon as possible, preferably from the start. This ensures a better integration within the organisation, and it makes the understanding of the necessity of the tools more obvious.

One of the important things to be aware of is the possibility to communicate within the system. This could be via e-mail, chat or some kind of conference or debate system. If implemented properly it can initiate discussions between colleagues and in the education give students the ability 
to argue any answer, question, solutions and suggestions in writing. The development of an asynchronous (teacher independent) communication for written argument and reflection between students provides an enhancement of the education. It puts a new perspective on the role of the teacher. It is also affected by and affects the culture of the learner depending on the communication medium used; chat, forum, e-mail, file sharing.

More and more people are involved in life long learning and increasingly post-school students access learning online. When you are involved in life long learning, you as 'teacher and student' should participate in the Life Long Design Process, particularly as teachers are no longer considered as the fount of all wisdom but are taking on the role of facilitator, guide and mentor. These roles are being well developed in the online environment, and as shown in the Danish case study above, often lead to greater student success rates.

\section{PROFESSIONAL DEVELOPMENT}

Core beliefs in learner centred learning acknowledge that learners have individual characteristics and learning styles, individual learning needs, and that learning often succeeds best in a collaborative environment. The digital world allows us to do new things in new ways. It imposes no limitations on the production, storage or access to material, opportunities for discourse, or time, manner and place of learning. We can be considered to be 'digitally minded' when we use synchronous and asynchronous tools to participate in co-operative and collaborative communities/relationships, re-examine the relationship between teacher and learner, and become more discerning and critically aware of information.

The major issues relating to using ICT for learning at a distance.

Technology Technology must be reliable and Helpdesk and Warranty covered. Technology must be available to anyone who wants it. Teachers and users need to be trained regularly as new hardware/software are released.

Support Teachers need time to write courses (perhaps training in multimedia), tools to write courses, to be valued for their contribution to the school, and need peer support (training, networks, attend conferences). Students need to be allowed to learn in chosen style, and appropriate technology tools.

Teaching and Learning Courses should reflect modern teaching and learning methods, including the use of appropriate technology (problem based, constructivist theory, project presentation). Courses need to promote 
innovation, and via ICT, courses should introduce experts, conduct regular classes, admin meetings, peer networks, conduct training.

Management Planning/negotiating curriculum between provider and student needs to be done centrally. Assessment needs to be decided centrally. Funding for technology/telecourses and course planning/implementation, should be available; evaluation must be done regularly.

\section{CONCLUSIONS}

In the final session, the group came together and agreed on a framework to encompass their discussions. The main focus was culture and how culture affected all aspects of the use of ICT, whether it referred to language, hardware, software or the view of the user. The major threads were:

- Culture of the hardware and software and the effect on users whose first language is not English

- Culture of the learner and the need to maintain indigenous and minority cultures and languages

- Support of the learner through mentoring, education and training

- Need for a learner-centred focus

- Communication and the interaction between teachers and students, students and students and teachers and teachers

- Collaboration and the balance with autonomous learning.

From these discussions the group concluded that we should be flexible in our use of IT in response to users, their culture, learning style and individual needs; we should plan course development with a view to quality and learning outcomes; and we should be respectful of the culture of learners in a global education market. We suggest that IFIP, backed by UNESCO, review ICT development from a cultural impact perspective.

\section{REFERENCES}

Charlier, B. and Peraya, D. (eds.) (2001, To be published) Learn-Net. Bruxelles, De Broeck. Leavitt, (1965)

Mason, R. (1998) Globalisation of Education. London, Routledge. 